\title{
Antifungal Applications of Ag-Decorated Hydroxyapatite Nanoparticles
}

\author{
C. A. Zamperini, ${ }^{1,2}$ R. S. André, ${ }^{3}$ V. M. Longo, ${ }^{1}$ E. G. Mima, ${ }^{2}$ C. E. Vergani, ${ }^{2}$ \\ A. L. Machado, ${ }^{2}$ J. A. Varela, ${ }^{1}$ and E. Longo ${ }^{1}$ \\ ${ }^{1}$ LIEC, UNESP-Univ Estadual Paulista, P.O. Box 355, 14801-907 Araraquara, SP, Brazil \\ ${ }^{2}$ Department of Dental Materials and Prosthodontics, Araraquara Dental School, UNESP-Univ Estadual Paulista, \\ 14801-903 Araraquara, SP, Brazil \\ ${ }^{3}$ LIEC, CMDMC, Department of Chemistry, Universidade Federal de São Carlos (UFSCar), 13565-905, São Carlos, SP, Brazil
}

Correspondence should be addressed to C. A. Zamperini; cazamperini@yahoo.com.br

Received 1 February 2013; Revised 23 May 2013; Accepted 26 May 2013

Academic Editor: Mohamed Bououdina

Copyright ( 2013 C. A. Zamperini et al. This is an open access article distributed under the Creative Commons Attribution License, which permits unrestricted use, distribution, and reproduction in any medium, provided the original work is properly cited.

\begin{abstract}
Pure hydroxyapatite (HA) and hydroxyapatite decorated with silver (HA@Ag) nanoparticles were synthesized and characterized. The antifungal effect of HA@Ag nanoparticles in a distilled water solution was evaluated against Candida albicans. The origin of the antifungal activity of the HA@Ag is also discussed. The results obtained showed that the HA nanorod morphology remained the same with Ag ions decorations on the HA structure which were deposited in the form of nanospheres. Interaction where occurred between the structure and its defect density variation in the interfacial HA@Ag and intrafacial HA region with the fungal medium resulted in antifungal activity. The reaction mechanisms involved oxygen and water adsorption which formed an active complex cluster. The decomposition and desorption of the final products as well as the electron/hole recombination process have an important role in fungicidal effects.
\end{abstract}

\section{Introduction}

$\mathrm{HA}, \mathrm{Ca}_{10}\left(\mathrm{PO}_{4}\right)_{6}(\mathrm{OH})_{2}$, is the major mineral component of human bone and other calcified tissues [1]. Thus, due to the similarity with bone composition and its ability to bond strongly with human hard tissue, the synthesis of HA (a bioceramic material) is of great interest for several clinical applications in the biomedical field $[2,3]$. Synthetic HA is a versatile inorganic material that also exhibits desirable properties such as biocompatibility, bioactivity, and osteoconductivity. In medicine and dentistry, due to its bioactive properties, HA has been successfully used for bone reconstructions and as coatings for dental implants; also, the structure is similar to the human bone mineral component. However, various sources of infections exist in these biomedical interventions, including environment surfaces and surgical equipment as well as microorganisms present in body tissues. Hence, the risk of infectious complications is high and may lead to failures which entail the need for subsequent surgery and medical costs in addition to the pain and suffering of patients. Candida albicans is among the most frequently isolated microorganisms from human infections, mainly in immunocompromised patients [4-6]. Although C. albicans is an eukaryotic commensal microorganism of human mucosal surfaces, when there is impairment of the host immunity, it can cause serious superficial and deep infections [4]. In general, the in vivo colonization of tissues and surfaces by microorganisms is related to biofilm formation. Biofilmassociated $C$. albicans cells are more resistant to antifungals commonly used compared to cells grown in planktonic form [5]. Therefore, the synthesis of HA with antifungal properties against planktonic and biofilm cells would be an important strategy to inhibit fungal colonization and, consequently, the incidence of surgical infections.

Researchers have reported that Ag-based compounds have broad-spectrum activity and a low propensity to induce microbial resistance. Silver nanoparticles (AgNPs) may attach to the cell membrane $[3,7]$ and cause structural 
changes, and, consequently, cell death. Additionally, the formation of free radicals [8] and the release of ions by nanoparticles may contribute to the antimicrobial activity of AgNP $[9,10]$. These results suggest that the incorporation of an antifungal agent such as AgNP on HA could be a step toward the formulation of new therapeutic agents.

Different synthesis methods have been reported in the literature to obtain HA crystals [11-13]. However, these procedures require long processing times as well as high temperatures which creates challenges in the development of a feasible method for the synthesis of HA nanocrystals. In this context, to obtain lower synthesis time and temperature requirements, the microwave-assisted hydrothermal (HTMW) [14, 15] method has been used in recent years and is one of the most promising methods to prepare nanomaterials with controlled size and shape [16]. Nevertheless, the challenge remains to prepare multicomponent or hybrid structures where two or more nanocrystal domains of different materials with individually tailored properties are integrated into one nanostructure.

Recently, the synthesis of Ag-doped nanocrystalline HA nanoparticles by a coprecipitation method has been reported and the antibacterial and antifungal activities were evaluated [17-19]. In these investigations, an antimicrobial effect was observed against Gram-negative and Gram-positive bacteria $[17,18]$ and Candida krusei, a fungal species [19]. In the present study, we report the synthesis of HA nanoparticles decorated with silver through a co-precipitation method with an HTMW treatment using calcium nitrate and ammonium phosphate as precursors. The silver was incorporated into the HA matrix after the synthesis.The HA@Ag powder was structurally characterized by high-resolution transmission electron microscopy (HR-TEM), X-ray diffraction (XRD), FT-Raman spectroscopy, and UV-visible spectroscopy (UVvis). The potential fungistatic and fungicidal effects of the HA@Ag in solution against C. albicans were evaluated by determining the minimum inhibitory concentration (MIC) and minimum fungicidal concentration (MFC). In addition, the effects of the HA@Ag solution against the biofilm formation of $C$. albicans were also evaluated. To the authors' knowledge, such effects of HA@Ag on C. albicans have not been widely evaluated [20].

\section{Experimental Section}

2.1. Materials and Synthesis. For the synthesis of HA, two aqueous solutions were prepared: a calcium nitrate tetrahydrate solution (Mallinckrodt, 99.9\%) and an ammonium phosphate solution (Mallinckrodit 99.4\%). The ammonium phosphate solution was then dripped into the calcium solution with constant agitation. The system was kept under flowing $\mathrm{N}_{2}$ throughout the mixing, and the $\mathrm{pH}$ solution was maintained at approximately 11 with the addition of ammonium hydroxide. The suspension containing the white solid precipitate was placed in a $100 \mathrm{~mL}$ Teflon autoclave which was sealed and loaded into the HTMW system using $2.45 \mathrm{GHz}$ microwave radiation with $800 \mathrm{~W}$ of power. The system was heated to $140^{\circ} \mathrm{C}$ and maintained at this temperature for 1 minute at a heating rate of $140^{\circ} \mathrm{C} / \mathrm{min}$ under constant pressure (approximately 3.0 bar). After treatment, the autoclave was naturally cooled to room temperature. The resultant product was washed with deionized water several times until a neutral pH was obtained and then dried in an oven.HA@Ag was synthesized using the previously prepared $\mathrm{HA}$ powder dispersed in distilled water, and the $\mathrm{pH}$ was adjusted to 5 with $\mathrm{HNO}_{3}$. The solution was stirred at $60^{\circ} \mathrm{C}$, and then $5 \mathrm{~mL}$ of $\mathrm{AgNO}_{3}$ solution $\left(1.4 \times 10^{-2} \mathrm{M}\right)$ was added. The precipitate was washed to $\mathrm{pH} 7$ and then again dried in an oven. The working concentration was $1 \mathrm{~mol} \mathrm{HA}: 1 \mathrm{~mol} \mathrm{Ag}$.

2.2. Characterization of the HA@Ag. Morphology and size characterizations were performed by transmission electron microscopy (TEM, Tecnai G2TF20, FEI). To confirm the presence of $\mathrm{Ag}$, an energy dispersive X-ray (EDX) measurement was taken in the same apparatus. All measurements were taken at room temperature. HA@Ag samples were characterized by XRD using a Rigaku DMax 2500PC diffractometer at $40 \mathrm{kV}$ and $150 \mathrm{~mA}$ with $\mathrm{Cu} \mathrm{K} \alpha$ radiation, a graphite monochromator, and a rotary anode. Raman spectra were recorded on a RFS/100/S Bruker Fourier transform Raman (FT-Raman) spectrometer with a $1064 \mathrm{~nm}$ excitation wavelength using a Nd:YAG laser in a spectral resolution of $4 \mathrm{~cm}^{-1}$. UV-vis absorption was recorded using a Cary $5 \mathrm{G}$ spectrometer in total reflectance mode by the integration cell.

\subsection{Antifungal Activity. C. albicans (ATCC 90028) was} grown in Sabouraud dextrose agar (SDA, Acumedia Manufacturers Inc., Baltimore, MD, USA) containing $5 \mu \mathrm{g} / \mathrm{mL}$ gentamicin for $48 \mathrm{~h}$ at $37^{\circ} \mathrm{C}$, followed by $21 \mathrm{~h}$ at $37^{\circ} \mathrm{C}$ in an RPMI-1640 culture medium. Cells of the resultant culture were harvested by centrifugation at $4000 \mathrm{~g}$ for $5 \mathrm{~min}$, washed twice with a phosphate-buffered saline solution (PBS; $\mathrm{pH}$ 7.2), and resuspended in the RPMI-1640 culture medium. The estimation of minimum inhibitory concentration (MIC) and minimum fungicidal concentration (MFC), using a broth microdilution assay [21], was used to evaluate the antifungal activity of the HA@Ag solution. The determination of MIC and MFC was used because it is a standard methodology for antimicrobial tests. C. albicans was incubated on a 96-well microtiter plate for 48 hours at $35^{\circ} \mathrm{C}$ and exposed to a serial two-fold dilution in the RPMI-1640 culture medium of the HA@Ag solution (from $1000 \mu \mathrm{g} / \mathrm{mL}$ to $3.90 \mu \mathrm{g} / \mathrm{mL}$ ). The MIC value was the lowest concentration of the HA@Ag solution which resulted in no visible growth (by visual inspection). Thereafter, aliquots from each well were diluted $\left(10^{-1}, 10^{-2}\right.$, $10^{-3}$, and $10^{-4}$ ) in PBS and inoculated on SDA (in duplicate) in order to establish the MFC. After $48 \mathrm{~h}$ at $37^{\circ} \mathrm{C}$, the colonyforming units per milliliter $(\mathrm{CFU} / \mathrm{mL})$ were calculated, and a $\log _{10}$ transformation was plotted. The MFC value was defined as the lowest concentration of the HA@Ag solution resulting in $99 \%$ reduction of fungal growth (UFC/mL). The assays were performed in triplicate on three separate occasions.

Additionally, the effects of the HA@Ag solution against biofilm formation of $C$. albicans also were evaluated. C. albicans suspensions were spectrophotometrically standardized in an RPMI-1640 culture medium at $1 \times 10^{7} \mathrm{CFU} / \mathrm{mL}$. Initially, $200 \mu \mathrm{L}$ aliquots were placed in each well of the 96-well 


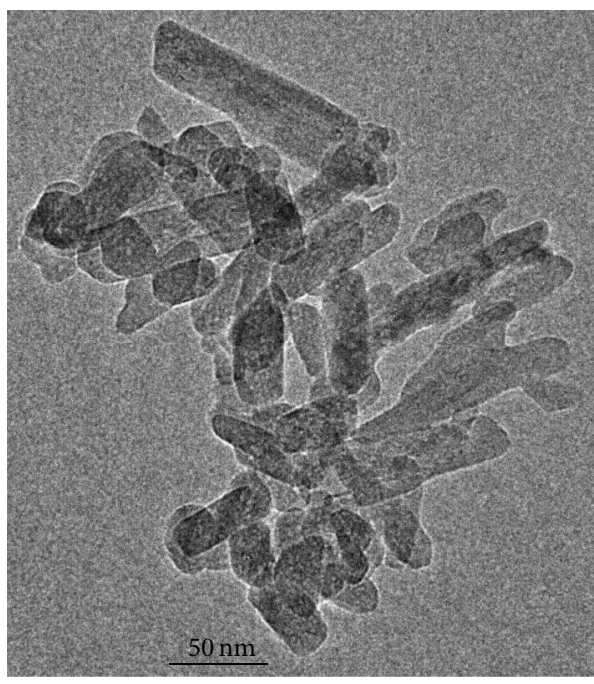

(a)

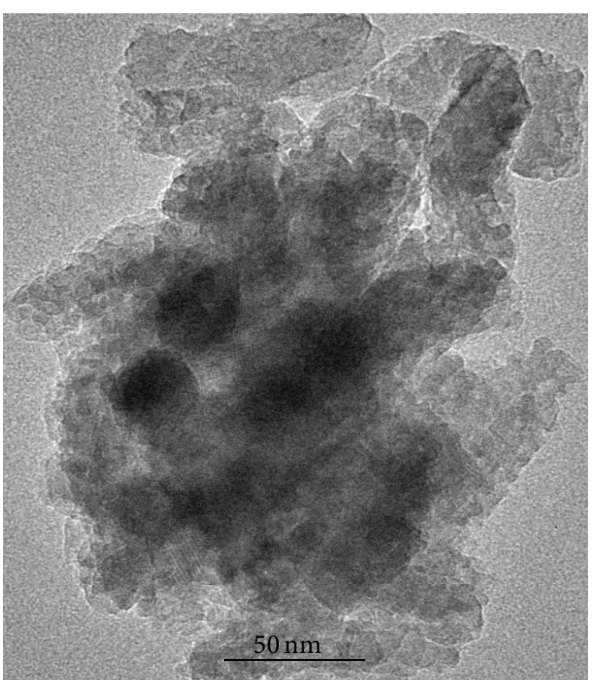

(b)

Figure 1: (a) TEM image of pure HA and (b) TEM image of HA@Ag.

microtiter plates and maintained for $90 \mathrm{~min}$ at $37^{\circ} \mathrm{C}$ (adhesion phase) in an orbital shaker [5]. Then, the loosely adhered cells were removed by washing twice with $200 \mu \mathrm{L}$ of PBS. Each one of the wells was filled with $200 \mu \mathrm{L}$ of fresh RPMI-1640 culture medium containing different concentrations of the HA@Ag solution (from $1000 \mu \mathrm{g} / \mathrm{mL}$ to $3.90 \mu \mathrm{g} / \mathrm{mL}$ ), and the plates were incubated at $37^{\circ} \mathrm{C}$ in an orbital shaker at $75 \mathrm{rpm}$ for $48 \mathrm{~h}$. After biofilm formation, the wells were carefully washed twice with $200 \mu \mathrm{L}$ of PBS to remove nonadherent cells.

The number of viable $C$. albicans and the total biomass of the biofilms exposed to different concentrations of the HA@Ag solution were evaluated by counting the colonies which formed units $(\mathrm{CFU} / \mathrm{mL})$ and measuring the absorbance of the crystal violet staining, respectively. To enumerate the $\mathrm{CFU} / \mathrm{mL}$, biofilms were scraped out of the wells of the 96-well microtiter plate and suspended by vigorous vortex mixing $(1 \mathrm{~min})$ in PBS. Thereafter, $10^{-1}, 10^{-2}$, $10^{-3}$, and $10^{-4}$ dilutions were performed, and aliquots of $25 \mu \mathrm{L}$ were inoculated on SDA plates (in duplicate). For the determination of the total biomass, the biofilms were fixed with methanol and stained with $1 \%$ violet crystal solution for $5 \mathrm{~min}$. The stain bonded to biofilm was dissolved in acetic acid at $33 \%$ and the optical density was measured $(570 \mathrm{~nm})$ using a spectrophotometer (Thermo Plate-TP Reader). Data obtained from CFU/mL quantification and total biomass were statistically analyzed by ANOVA and Tukey's post hoc tests at $5 \%$ of significance.

The morphological characteristics of the biofilms formed in the presence of the HA@Ag solution also were evaluated using a field emission gun-scanning electron microscopy (FEG-SEM). For this procedure, C. albicans biofilms were cultured and exposed to different concentrations of HA@Ag solution on the bottom of a 24 -well plate, as described previously. Following biofilm formation, these products were fixed with $2.5 \%$ glutaraldehyde in PBS for 24 hours, dehydrated in increasing concentrations of ethanol (70\%, 85\%, and 90\%) for 5 min each and observed in FEG-SEM (Jeol, JSM 7500 F).

\section{Results and Discussion}

Figure 1 shows TEM morphologies of pure HA and the HA@Ag synthesized under the same conditions, respectively. Figure 1 shows that there was very little difference between the two samples in particle size and morphologies. The pure HA (see Figure 1(a)) has a nanorod structure with a diameter varying from 12 to $27 \mathrm{~nm}$. A closer look at a comparatively thin rod plate which provides sufficient transparency of electrons for high resolution is provided in Figure 2; a layered structure is apparent.

However, silver is observed in the nanospherical morphology with an interplanar distance of $0.276 \mathrm{~nm}$ which corresponds to the $\mathrm{Ag}$ (111) plane (the preferential growth plane) (see Figure 2(c)) according to the JCPDS 65-2871. The EDX spectrum of HA@Ag confirms calcium (Ca), phosphor (P), oxygen $(\mathrm{O})$, and silver (Ag) in the samples (see Figure 2(a)). The presence of copper $(\mathrm{Cu})$ and silicon $(\mathrm{Si})$ was attributed to the sample grid support.

The characterization in a long-range order of the pure HA and HA@Ag samples was performed by XRD (see Figures 3(a) and 3(b), resp.). The HA single phase formation has a hexagonal structure with a $\mathrm{P}$ 63/m space group even with Ag. No planes related to the Ag phase were located. Secondary phases such as calcium carbonate, $\mathrm{CaCO}_{3}$, were not found in XRD results.

The HA@Ag structure in a short-range order was performed by FT-Raman analyses as a complementary structural study for XRD data. Raman spectra at room temperature in the frequency range of 400 to $1200 \mathrm{~cm}^{-1}$ for the HA@Ag powder processed in the HTMW system during $1 \mathrm{~min}$ are displayed in Figure 4. According to Penel et al. [22], all 


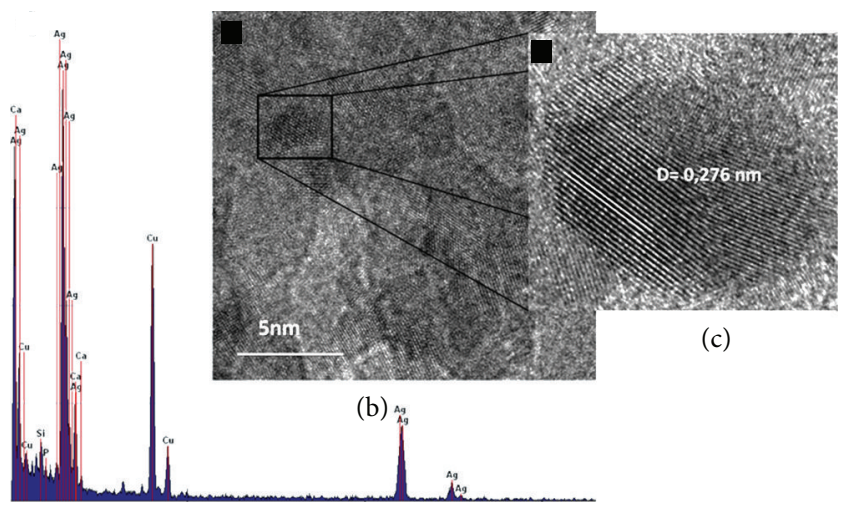

(a)

Figure 2: (a) An EDX measurement of HA@Ag nanoparticles; (b) HRTEM image of Ag nanospheres; and (c) a zoom of a nanoparticle with (111) interplanar distance.

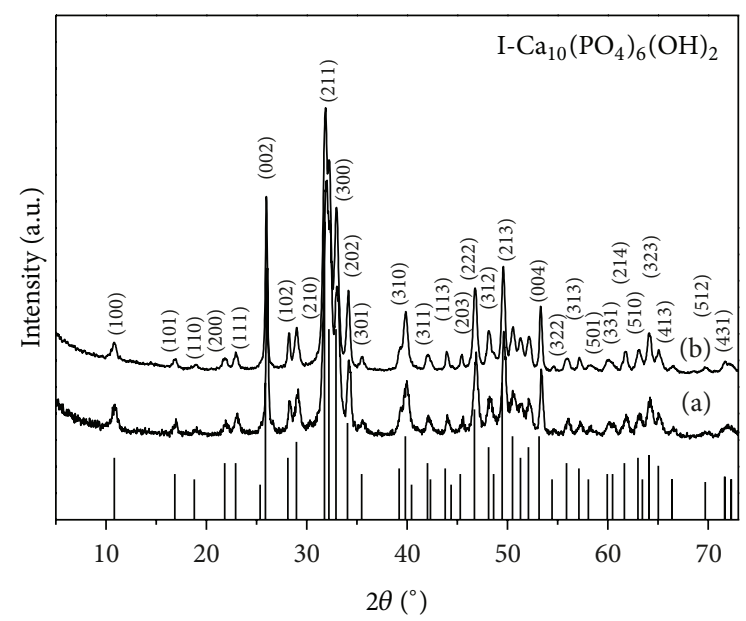

FIgURE 3: XRD patterns for (a) pure HA and (b) HA@Ag sample.

Raman modes are related to the HA phase. From Raman studies on carbonated apatite, two distinct wavenumbers of the $v_{1}$ carbonate mode have been suggested according to $\mathrm{OH}^{-}$or $\mathrm{PO}_{4}{ }^{3-}$ site substitution at 1108 and $1070 \mathrm{~cm}^{-1}$, respectively. Variable numbers of bands in the $v_{1} \mathrm{PO}_{4}{ }^{3-}$ domain were also detected by the authors [22]. Since none of these characteristics were found in the Raman spectrum (see Figure 4), we conclude that the HA@Ag obtained does not present the concurrent calcium carbonate phase as a second phase which agrees with XRD results that indicate the HA single phase formation.

A UV-vis analysis was conducted (see Figures 5(a) and 5(b)) to determine the electronic structure of HA@Ag. Moreover, the GAP energy was calculated by using the Wood and Tauc method from the UV-spectra for pure HA and HA@Ag. The values obtained were $4.7 \mathrm{eV}$ for pure $\mathrm{HA}$ and $3.6 \mathrm{eV}$ for HA@Ag. There is a significant difference between band gap values for both samples. The exponential optical absorption edge and the optical band gap energy are controlled by the degree of structural disorder in the lattice. The decrease in the

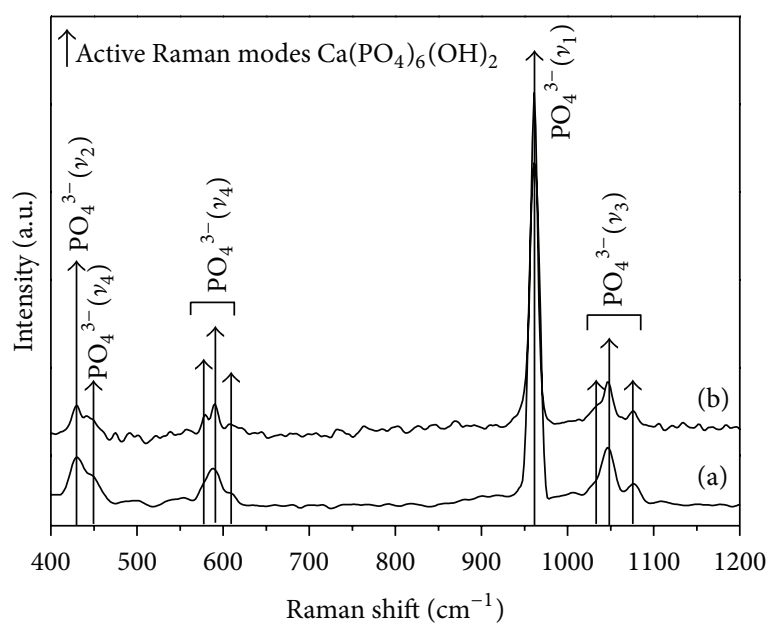

Figure 4: FT-Raman spectra for (a) pure HA and (b) HA@Ag.

band gap can be attributed to defects, local bond distortion, and intrinsic surface and/or interface states (HA and $\mathrm{Ag}$ ) which yield localized electronic levels in the forbidden band gap.

We believe that this significant difference is attributed to Ag surface defects and (HA@Ag) interface defects [23] (see Figure 6).

MIC and MFC values were $62.5 \mu \mathrm{g} / \mathrm{mL}$ and $250 \mu \mathrm{g} / \mathrm{mL}$, respectively (Figure 7). These results demonstrate that the HA@Ag solution has fungistatic and fungicidal effects against the microorganism tested and thus indicate that it may be a potential candidate for developing new antimicrobial agents with multiple applications in the biomedical field. Although these MIC and MFC values against C. albicans are higher than those values obtained with commonly used antifungal agents [5] and different nanoparticles [24-26], other important aspects should be considered. First, when composites are used, the concentrations of individual nanoparticles can be decreased as well as the cytotoxicity to eukaryotic human cells [27]. Moreover, in this study, the amount of $\mathrm{AgNO}_{3}$ used was $7.10^{-5} \mathrm{~mol}$ with a $\mathrm{Ag} / \mathrm{HA}$ ratio of 1 . Hence, the combination of different nanoparticles could have a positive impact in avoiding the development of microbial resistance [27].

Bearing in mind the biofilm architecture and its role on resistance against antimicrobial agents, it was considered important to evaluate the possible effects of the HA@Ag solution against cells and extracellular polymeric matrix. The results demonstrated that, when the $C$. albicans biofilms were exposed to different concentrations of the HA@Ag solution, a significant reduction in the number of $\mathrm{CFU} / \mathrm{mL}$ was observed only at a concentration of $1000 \mu \mathrm{g} / \mathrm{mL}$ (see Figure 8). This result can be attributed to the higher resistance of $C$. albicans cells grown in biofilms $[5,24-26]$. Although mechanisms of biofilm drug resistance are not fully understood, factors such as decreased growth rate, expression of resistance genes, and an extracellular polymeric matrix can contribute to increased tolerance of cells in biofilms [28].The biofilm matrix acts as a barrier, protecting the deep layers of cells. Recently, Ciobanu et al. [19] evaluated the effect of nanosized particles 


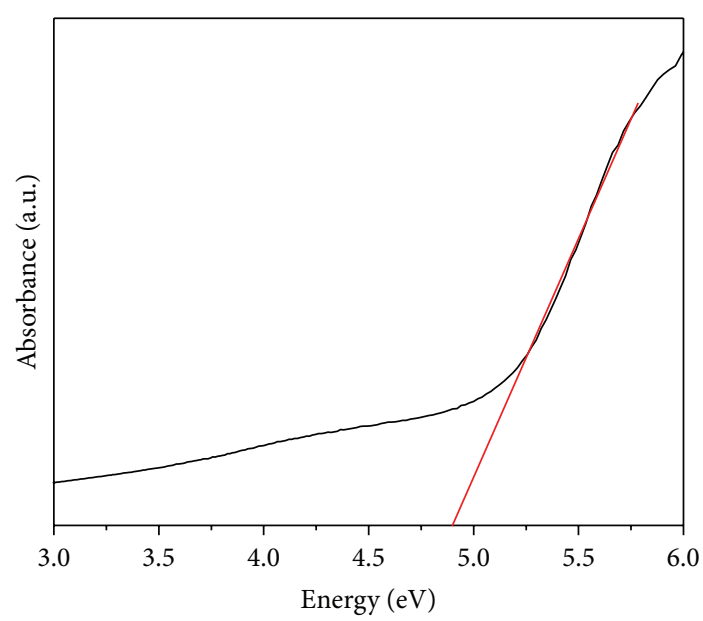

(a)

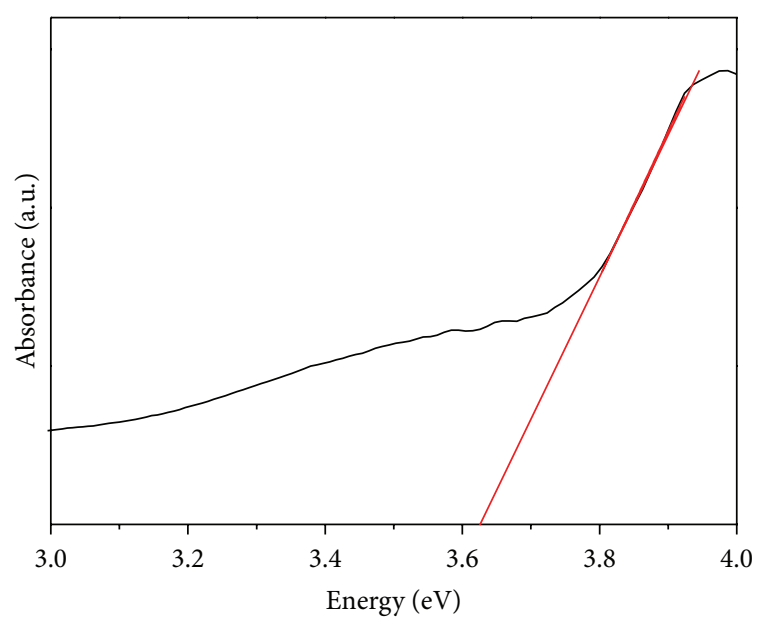

(b)

FIGURE 5: UV-vis absorbance spectra for (a) pure HA and (b) HA@Ag samples.

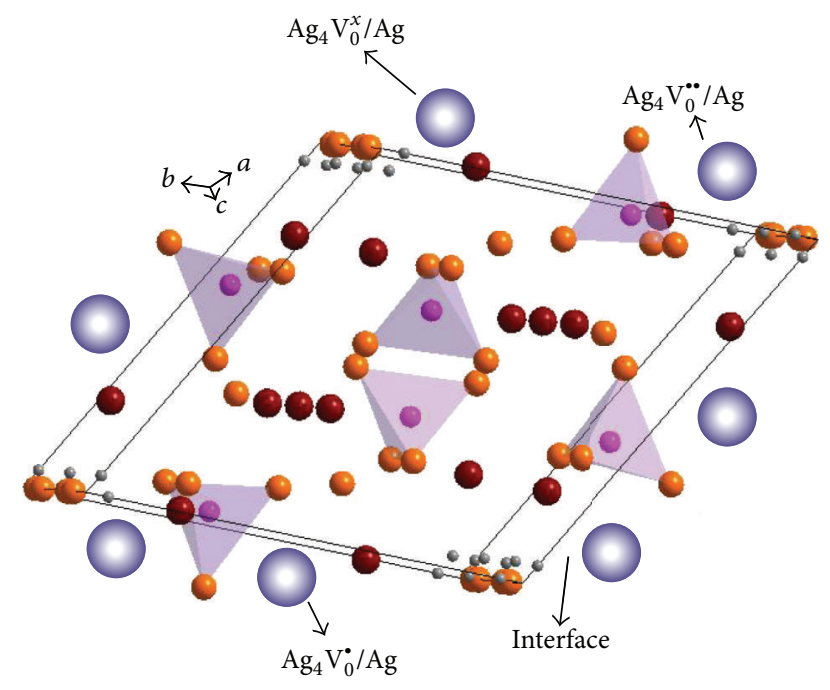

$\begin{array}{lll}\mathrm{Ca}^{2+} & \mathrm{O}^{2-} \\ \mathrm{P}^{5+} & \mathrm{H}^{1+}\end{array}$

FIGURE 6: Illustration of the system with the formation of a complex cluster $\left[\mathrm{Ag}_{4}\right]_{\mathrm{d}}$.

of Ag-doped HA on the first step of bacterial adherence to the inert substratum and on a $24 \mathrm{~h}$ preformed biofilm. These authors also observed that the inhibitory effect against biofilm formation was dependent on the concentration of the nanoparticles evaluated. Other recent studies that evaluated the effect of silver nanoparticles against $C$. albicans biofilms also observed a high tolerance of this fungal specie grown in biofilms when compared to planktonic cells [24-26].

The results obtained after crystal violet staining showed significant decreases of the total biomass values when C. albicans biofilms were exposed to HA@Ag solution at concentrations of $1000 \mu \mathrm{g} / \mathrm{mL}, 500 \mu \mathrm{g} / \mathrm{mL}$, and $250 \mu \mathrm{g} / \mathrm{mL}$ (see Figure 9), showing clearly that the HA@Ag solution

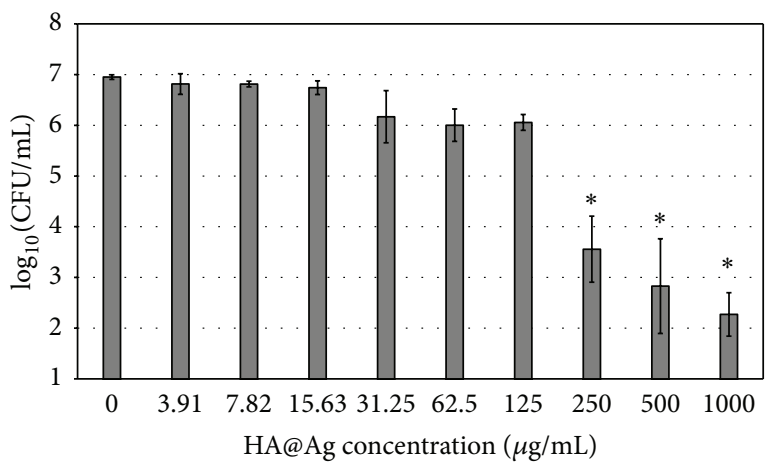

Figure 7: Mean values of $\log _{10}(\mathrm{CFU} / \mathrm{mL})$ of planktonic cultures of C. albicans exposed to HA@Ag solution. Errors bars: standard deviation. ${ }^{*}$ : significant differences compared with control $(0 \mu \mathrm{g} / \mathrm{mL})$.

affected the extracellular matrix production. This result is important because biofilm formation is one of the major virulence factors of $C$. albicans, and its reduction makes the microorganisms more susceptible to antifungal agents and more vulnerable to host defense mechanisms. Although the biofilms matrix was reduced by the HA@Ag solution, this effect was not observed in the terms of CFU/mL. This finding suggests that the cells exhibit recovery ability after the plating, and thus, the HA@Ag solution can have a temporary and reversible effect against $C$. albicans biofilms. These results are in agreement with those observed in a recent study in which Ag nanoparticles were effective in reducing biofilm biomass when applied to biofilms of C. albicans and C. glabrata. However, the effect of Ag nanoparticles in the number of viable biofilm cells of $C$. albicans was less evident [26].

Moreover, the results obtained also demonstrated that the total biomass values of $C$. albicans biofilms exposed to concentrations of 7.82 and $3.91 \mu \mathrm{g} / \mathrm{mL}$ of the HA@Ag solution were significantly higher as compared with the control $(0 \mu \mathrm{g} / \mathrm{mL})$. It has been reported that subinhibitory concentrations of antimicrobial agents could up regulate 


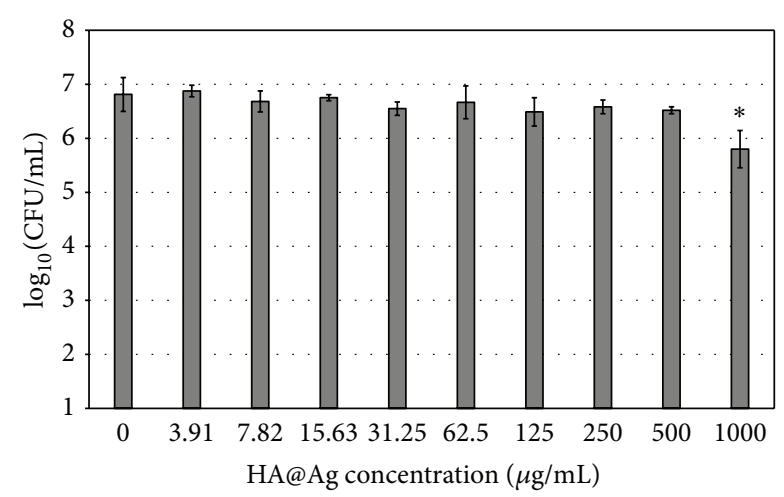

Figure 8: Mean values of $\log _{10}(\mathrm{CFU} / \mathrm{mL})$ of C. albicans biofilm exposed to HA@Ag solution. Errors bars: standard deviation. * : significant difference compared with control $(0 \mu \mathrm{g} / \mathrm{mL})$.

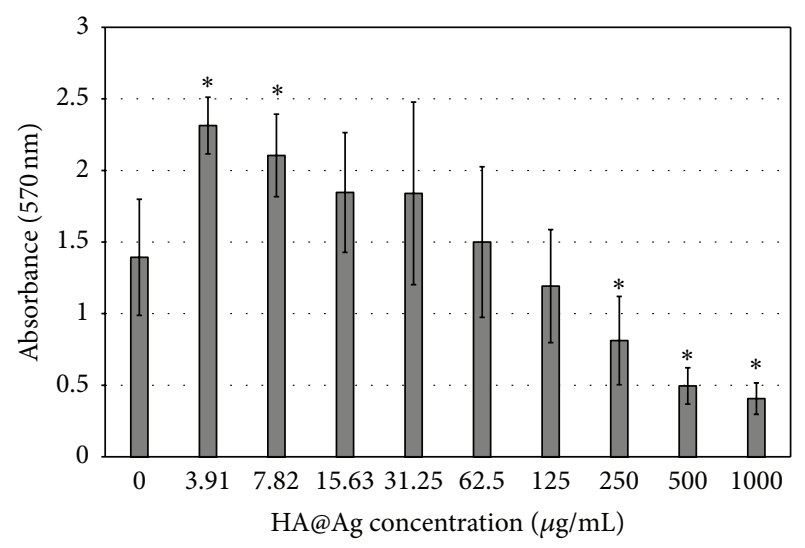

FIGURE 9: Total biomass of C. albicans biofilms exposed to HA@Ag solution. Errors bars: standard deviation. ${ }^{*}$ : significant differences compared with control $(0 \mu \mathrm{g} / \mathrm{mL})$.

genes related to virulence factors, such as enzyme production [29] and biofilm formation [30].

FEG-SEM images confirm the quantitative outcomes obtained with biofilms (see Figure 10) since alterations in cell morphology ("shriveled" cells appearance) were observed proportional to the concentration of HA@Ag nanoparticles. However, as can be seen in Figure 10, some intact cells remain even in the presence of high concentrations of nanoparticles. Micrographs with none (control) or low HA@Ag content showed more cell aggregates and higher quantity of hyphal cells. C. albicans is able to change its morphology between yeast and filamentous (hyphae and pseudohyphae) forms in a process called polymorphism. Hyphal cells are responsible for infection in the host and are able to invade tissues. These findings show that the HA@Ag solution exhibited an antifungal property against $C$. albicans biofilms.

The performance of HA and silver is primarily dictated not only by physicochemical and mechanical properties, but also by biological activity [31]. HA is known as a biocompatible ceramic, and Ag has long been studied as an antimicrobial agent which has been successfully used in biomedical prosthesis and surgical instruments [31-35]. The antimicrobial activity of $\mathrm{Ag}$ can be explained in many ways. It has been reported that $\mathrm{Ag}$ ions can damage the bacterial outer membrane which causes cell death [34-36]. A similar mechanism seems to occur for C. albicans. Kim et al. [37] reported a potent antifungal effect of Ag nanoparticles against C. albicans with MIC values similar to amphotericin B. In this study [37], several methodologies such as flow cytometry analysis, glucose and trehalose release, plasma membrane fluorescence anisotropy, and transmission electron microscopy (TEM) were used to elucidate the mechanism of antifungal action. Membrane depolarization, the arrest of the fungal cell cycle by flow cytometry, the release of intracellular glucose and trehalose, a decrease in plasma membrane fluorescence with increasing concentrations of Ag nanoparticles, pits in the cell wall, and pores in the plasma membrane on the TEM images were observed. These findings demonstrate that $\mathrm{Ag}$ nanoparticles destruct the fungal membrane integrity and inhibit the normal budding process.

Disorders in surfaces and interfaces occur in HA@Ag synthesized by the HTMW method and create disordered sites [38]. This fact induces restructuring at the intermediate range which results in structural and electronic alterations to both the surface and interface. Disordered sites yield a local lattice distortion that is propagated along the overall material which pushes the surrounding clusters away from their ideal positions. Thus, complex clusters (disordered clusters) must move for these properties to occur which changes the electronic distribution along the network of these polar clusters [39]. This electronic structure may dictate the biological activity and plays a major role in determining the reactivity and stability of the cluster.

The mechanism of cluster complex $\left[\mathrm{Ag}_{4}\right]^{\cdot}$ activity with oxygen essentially depends on the complex cluster with the formation of a superoxide and/or a hydroxyl radical. $\left[\mathrm{Ag}_{4}\right]_{\mathrm{d}}^{\cdot}$ and $\left[\mathrm{Ag}_{4}\right]_{\mathrm{d}}^{\prime}$ can create hydroxyl radicals $\left(\mathrm{OH}^{*}\right)$ and superoxide anions $\left(\mathrm{O}_{2} \mathrm{H}^{*}\right)$ by electron/hole reactions which can facilitate protein inactivation and eventual cell apoptosis where $\mathrm{d}=$ disorder and $\mathrm{O}=$ order.

Moreover, an effective charge separation requires an electric field between the sample bulk and surface. Consequently, the effect of surface properties on electron/hole reaction performance should be considered in terms of the following:

$$
\left[\mathrm{Ag}_{4}\right]_{0}^{x}+\left[\mathrm{Ag}_{4}\right]_{\mathrm{d}}^{x} \longrightarrow\left[\mathrm{Ag}_{4}\right]_{\mathrm{d}}^{\prime}+\left[\mathrm{Ag}_{4}\right]_{\mathrm{d}}^{\bullet}
$$

The reactivity of molecular oxygen with a complex cluster $\left.\left[\mathrm{Ag}_{4}\right]_{\mathrm{d}}\right]^{\circ}$ on the surface of silver oxide results in a chemisorbed species and subsequent oxygen incorporation into the lattice:

$$
\begin{gathered}
{\left[\mathrm{Ag}_{4}\right]_{\mathrm{d}}^{\cdot}+\mathrm{O}_{2} \longrightarrow\left[\mathrm{Ag}_{4}\right]_{\mathrm{d}}^{\bullet} \cdots \mathrm{O}_{2(\mathrm{ads})}} \\
{\left[\mathrm{Ag}_{4}\right]_{\mathrm{d}}^{\cdot} \cdots \mathrm{O}_{2(\mathrm{ads})}+\left[\mathrm{Ag}_{4}\right]_{0}^{\prime} \longrightarrow\left[\mathrm{Ag}_{4}\right]_{\mathrm{d}}^{\cdot} \cdots \mathrm{O}_{2(\mathrm{ads})}^{\prime}+\left[\mathrm{Ag}_{4}\right]_{0}^{x}}
\end{gathered}
$$




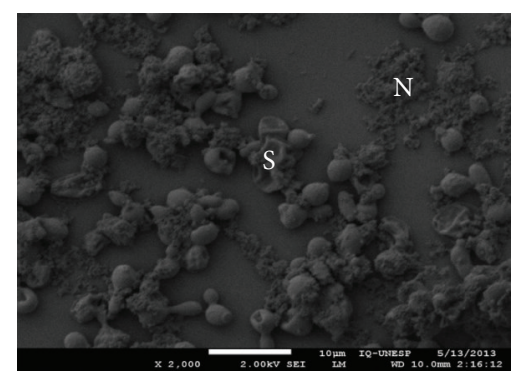

(a)

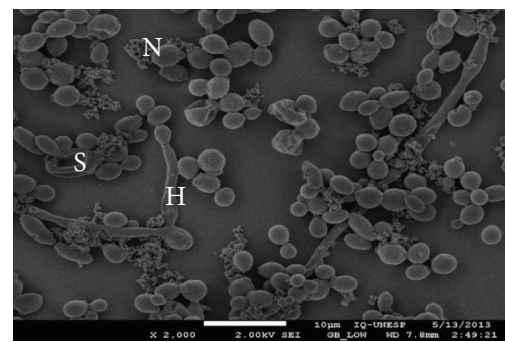

(d)

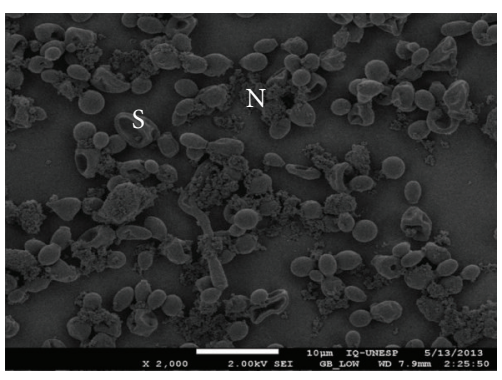

(b)

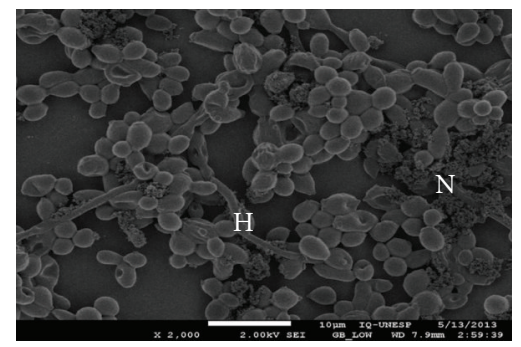

(e)

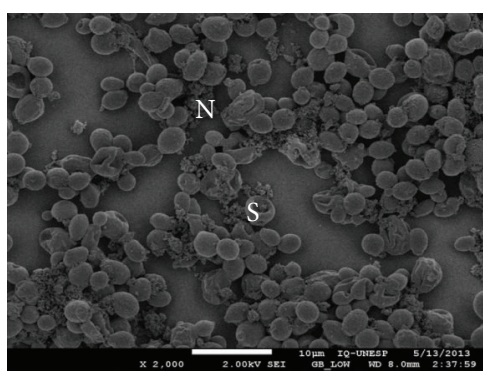

(c)

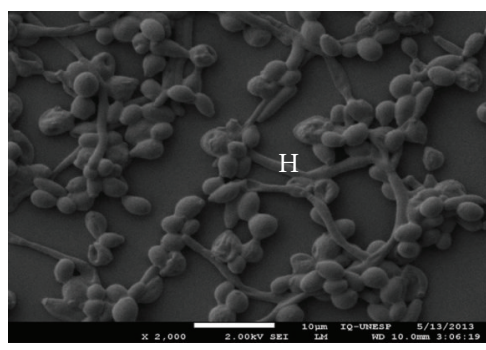

(f)

Figure 10: FEG-SEM of C. albicans biofilms with different concentrations of the HA@Ag solution: (a) 1000, (b) 500, (c) 250, (d) 125, (e) 62.5, and (f, control) $0 \mu \mathrm{g} / \mathrm{mL} . \mathrm{N}$ : HA@Ag nanoparticles, S: "shriveled" cells appearance, H: Hyphae.

The clusters formed by the complex silver oxide also interact with water and split into hydroxyl radicals and hydrogen ions according to the following reactions:

$$
\begin{gathered}
{\left[\mathrm{Ag}_{4}\right]^{\bullet}+\mathrm{H}_{2} \mathrm{O} \longrightarrow\left[\mathrm{Ag}_{4}\right]^{\bullet} \cdots \mathrm{H}_{2} \mathrm{O}_{(\mathrm{ads})}} \\
{\left[\mathrm{Ag}_{4}\right]^{\bullet} \cdots \mathrm{H}_{2} \mathrm{O}_{(\mathrm{ads})} \longrightarrow\left[\mathrm{Ag}_{4}\right]^{\bullet} \cdots \mathrm{OH}^{*}{ }_{(\mathrm{ads})}+\mathrm{H}^{\bullet}}
\end{gathered}
$$

Products of the partial oxidation reaction between water and a complex cluster $\left[\mathrm{Ag}_{4}\right]_{\mathrm{d}}^{\circ}$ are hydroxyl radicals, $\mathrm{OH}^{*}$, and hydrogen ions. These radicals exhibit high oxidation power which produces a microorganism mineralization in water (anodic oxidation) (5).

Primary reaction (cathodic) is the formation of a superoxide species $\left[\mathrm{Ag}_{4}\right]_{\mathrm{d}}^{\circ} \cdots \mathrm{O}_{2}^{\prime}(2)$ and (3). These species then react with $\mathrm{H}^{\bullet}(5)$ and produce the formation of hydrogen peroxide radicals $\left(\mathrm{HO}_{2}{ }^{*}\right)$ according to the following reactions:

$$
\left[\mathrm{Ag}_{4}\right]_{\mathrm{d}}^{\bullet} \cdots \mathrm{O}_{2(\mathrm{ads})}^{\prime}+\mathrm{H}^{\bullet} \longrightarrow\left[\mathrm{Ag}_{4}\right]_{\mathrm{d}}^{\bullet} \cdots \mathrm{O}_{2} \mathrm{H}_{(\mathrm{ads})}^{*}
$$

The radicals $\mathrm{OH}^{*}$ and $\mathrm{O}_{2} \mathrm{H}^{*}$ may react with the fungal cells which ultimately results in their oxidation.

The nature of the superoxide or hydroxyl radicals can be described using a complex cluster model where the electron transfer from the surface to the adsorbed molecular oxygen occurs [40-42].

These reaction mechanisms involve oxygen and water adsorptions that form an active complex cluster. Its decomposition, desorption of the final products, and the electron hole recombination process may have an important role in fungicidal effects.

Therefore,HA@Ag was successfully obtained by maintaining the structure of HA nanorods overlapped by nanosphere Ag as confirmed by TEM images. The HA@Ag obtained shows efficient antifungal action. The results of antifungal tests can be explained by the interaction between the structure and the defect density variation in the interfacial (HA@Ag) and intrafacial (HA) region with the fungal medium which results in antifungal activity.

\section{Conclusions}

HA@Ag was successfully obtained by maintaining the HA nanorods structure overlapped by nanosphere Ag through a co-precipitation method with HTMW. The HA@Ag solution showed fungistatic and fungicidal effects against C. albicans planktonic cells with MIC and MFC values of $62.5 \mu \mathrm{g} / \mathrm{mL}$ and $250 \mu \mathrm{g} / \mathrm{mL}$, respectively. Additionally, the HA@Ag solution at concentrations of $1000 \mu \mathrm{g} / \mathrm{mL}, 500 \mu \mathrm{g} / \mathrm{mL}$, and $250 \mu \mathrm{g} / \mathrm{mL}$ also exhibited antibiofilm activity, affecting mainly the extracellular matrix production. The morphological characteristics of cells were altered, and the density of hyphal cells was less noticeable in presence of the HA@Ag solution at higher concentrations. A mechanism was proposed to justify the antifungal activity by the interaction between the structure and the defect density variation in the interfacial (HA@Ag) and intrafacial (HA) region with the fungal medium.

\section{Acknowledgment}

This research was supported by grants 2011/06786-0, and 2011/24004-0, São Paulo Research Foundation (FAPESP).

\section{References}

[1] K. P. Tank, P. Sharma, D. K. Kanchan, and M. J. Joshi, "FTIR, powder XRD, TEM and dielectric studies of pure and zinc 
doped nano-hydroxyapatite," Crystal Research and Technology, vol. 46, no. 12, pp. 1309-1316, 2011.

[2] N. Rameshbabu, T. S. S. Kumar, T. G. Prabhakar, V. S. Sastry, K. V. G. K. Murty, and K. Prasad Rao, "Antibacterial nanosized silver substituted hydroxyapatite: synthesis and characterization," Journal of Biomedical Materials Research A, vol. 80, no. 3, pp. 581-591, 2007.

[3] M. Miranda, A. Fernández, S. Lopez-Esteban, F. Malpartida, J. S. Moya, and R. Torrecillas, "Ceramic/metal biocidal nanocomposites for bone-related applications," Journal of Materials Science, vol. 23, no. 7, pp. 1655-1662, 2012.

[4] R. Manfredi, S. Sabbatani, and L. Calza, "Recurring Candida albicans esophagitis in a HIV-infected patient undergoing long-term antiretroviral therapy, and with absent-negligible immunodeficiency," Brazilian Journal of Infectious Diseases, vol. 11, no. 6, pp. 605-609, 2007.

[5] J. Chandra, P. K. Mukherjee, S. D. Leidich et al., "Antifungal resistance of candidal biofilms formed on denture acrylic in vitro," Journal of Dental Research, vol. 80, no. 3, pp. 903-908, 2001.

[6] P. Badiee and A. Alborzi, "Invasive fungal infections in renal transplant recipients," Experimental and Clinical Transplantation, vol. 9, no. 6, pp. 355-362, 2011.

[7] I. Sondi and B. Salopek-Sondi, "Silver nanoparticles as antimicrobial agent: a case study on E. coli as a model for Gramnegative bacteria," Journal of Colloid and Interface Science, vol. 275, no. 1, pp. 177-182, 2004.

[8] J. S. Kim, E. Kuk, K. N. Yu et al., "Antimicrobial effects of silver nanoparticles," Nanomedicine, vol. 3, no. 1, pp. 95-101, 2007.

[9] J. R. Morones, J. L. Elechiguerra, A. Camacho et al., "The bactericidal effect of silver nanoparticles," Nanotechnology, vol. 16, no. 10, pp. 2346-2353, 2005.

[10] M. A. Afzal, S. Kalmodia, P. Kesarwani, B. Basu, and K. Balani, "Bactericidal effect of silver-reinforced carbon nanotube and hydroxyapatite composites," Journal of Biomaterials Applications, vol. 27, no. 8, pp. 967-978, 2012.

[11] Z. Lu, Y. Liu, B. Liu, and M. Liu, "Friction and wear behavior of hydroxyapatite based composite ceramics reinforced with fibers," Materials and Design, vol. 39, pp. 444-449, 2012.

[12] D. Gopi, J. Indira, L. Kavitha, M. Sekar, and U. K. Mudali, "Synthesis of hydroxyapatite nanoparticles by a novel ultrasonic assisted with mixed hollow sphere template method," Spectrochimica Acta A, vol. 93, pp. 131-134, 2012.

[13] F. Ren, Y. Ding, X. Ge, X. Lu, K. Wang, and Y. Leng, "Growth of one-dimensional single-crystalline hydroxyapatite nanorods," Journal of Crystal Growth, vol. 349, no. 1, pp. 75-82, 2012.

[14] H. E. Wang, L. J. Xi, R. G. Ma et al., "Microwave-assisted hydrothermal synthesis of porous $\mathrm{SnO}_{2}$ nanotubes and their lithium ion storage properties," Journal of Solid State Chemistry, vol. 190, pp. 104-110, 2012.

[15] V. D. Maksimov, P. E. Meskin, and B. R. Churagulov, "Microwave-assisted hydrothermal synthesis of fine $\mathrm{BaZrO}_{3}$ and $\mathrm{BaHfO}_{3}$ powders," Inorganic Materials, vol. 43, no. 9, pp. 988-993, 2007.

[16] V. D. Araújo, W. Avansi, H. B. de Carvalho et al., " $\mathrm{CeO}_{2}$ nanoparticles synthesized by a microwave-assisted hydrothermal method: evolution from nanospheres to nanorods," CrystEngComm, vol. 14, no. 3, pp. 1150-1154, 2012.

[17] C. S. Ciobanu, F. Massuyeau, L. V. Constantin, and D. Predoi, "Structural and physical properties of antibacterial Ag-doped nano-hydroxyapatite synthesized at $100^{\circ} \mathrm{C}$," Nanoscale Research Letters, vol. 6, no. 1, article 613, pp. 1-8, 2011.
[18] C. S. Ciobanu, S. L. Iconaru, P. le Coustumer, L. V. Constantin, and D. Predoi, "Antibacterial activity of silver-doped hydroxyapatite nanoparticles against gram-positive and gram-negative bacteria," Nanoscale Research Letters, vol. 7, no. 1, article 324, 2012.

[19] C. S. Ciobanu, S. L. Iconaru, M. C. Chifiriuc, A. Costescu, P. le Coustumer, and D. Predoi, "Synthesis and antimicrobial activity of silver-doped hydroxyapatite nanoparticles," BioMed Research International, vol. 2013, Article ID 916218, 10 pages, 2013.

[20] V. Stanić, D. Janaćković, S. Dimitrijević et al., "Synthesis of antimicrobial monophase silver-doped hydroxyapatite nanopowders for bone tissue engineering," Applied Surface Science, vol. 257, no. 9, pp. 4510-4518, 2011.

[21] CLSI, Reference Method for Broth Dilution Antifungal Susceptibility Testing of Yeasts; Approved Standard, CLSI Document M27-A3, Clinical and Laboratory Standards Institute, Wayne, Pa, USA, 3rd edition, 2008.

[22] G. Penel, G. Leroy, C. Rey, and E. Bres, "MicroRaman spectral study of the $\mathrm{PO}_{4}$ and $\mathrm{CO}_{3}$ vibrational modes in synthetic and biological apatites," Calcified Tissue International, vol. 63, no. 6, pp. 475-481, 1998.

[23] C. W. Raubach, Y. V. B. de Santana, M. M. Ferrer et al., "Strutural and optical approach of CdS@ZnS core-shell system," Chemical Physics Letters, vol. 536, pp. 96-99, 2012.

[24] A. F. Wady, A. L. Machado, V. Zucolotto, C. A. Zamperini, E. Berni, and C. E. Vergani, "Evaluation of Candida albicans adhesion and biofilm formation on a denture base acrylic resin containing silver nanoparticles," Journal of Applied Microbiology, vol. 112, no. 6, pp. 1163-1172, 2012.

[25] D. R. Monteiro, S. Silva, M. Negri et al., "Silver nanoparticles: influence of stabilizing agent and diameter on antifungal activity against Candida albicans and Candida glabrata biofilms," Letters in Applied Microbiology, vol. 54, no. 5, pp. 383-391, 2012.

[26] D. R. Monteiro, L. F. Gorup, S. Silva et al., "Silver colloidal nanoparticles: antifungal effect against adhered cells and biofilms of Candida albicans and Candida glabrata," Biofouling, vol. 27, no. 7, pp. 711-719, 2011.

[27] M. A. Vargas-Reus, K. Memarzadeh, J. Huang, G. G. Ren, and R. P. Allaker, "Antimicrobial activity of nanoparticulate metal oxides against peri-implantitis pathogens," International Journal of Antimicrobial Agents, vol. 40, no. 2, pp. 135-139, 2012.

[28] G. Ramage, E. Mowat, B. Jones, C. Williams, and J. Lopez-Ribot, "Our current understanding of fungal biofilms," Critical Reviews in Microbiology, vol. 35, no. 4, pp. 340-355, 2009.

[29] T. Wu, K. Wright, S. F. Hurst, and C. J. Morrison, "Enhanced extracellular production of aspartyl proteinase, a virulence factor, by Candida albicans isolates following growth in subinhibitory concentrations of fluconazole," Antimicrobial Agents and Chemotherapy, vol. 44, no. 5, pp. 1200-1208, 2000.

[30] L. Dong, Z. Tong, D. Linghu et al., "Effects of sub-minimum inhibitory concentrations of antimicrobial agents on Streptococcus mutans biofilm formation," International Journal of Antimicrobial Agents, vol. 39, no. 5, pp. 390-395, 2012.

[31] M. Roy, G. A. Fielding, H. Beyenal, A. Bandyopadhyay, and S. Bose, "Mechanical, in vitro antimicrobial, and biological properties of plasma-sprayed silver-doped hydroxyapatite coating," ACS Applied Materials and Interfaces, vol. 4, no. 3, pp. 1341-1349, 2012.

[32] A. Ewald, D. Hösel, S. Patel, L. M. Grover, J. E. Barralet, and U. Gbureck, "Silver-doped calcium phosphate cements with antimicrobial activity," Acta Biomaterialia, vol. 7, no. 11, pp. 4064-4070, 2011. 
[33] N. Matsumoto, K. Sato, K. Yoshida, K. Hashimoto, and Y. Toda, "Preparation and characterization of $\beta$-tricalcium phosphate co-doped with monovalent and divalent antibacterial metal ions," Acta Biomaterialia, vol. 5, no. 8, pp. 3157-3164, 2009.

[34] W.-H. Song, S. R. Hyun, and S.-H. Hong, "Antibacterial properties of $\mathrm{Ag}$ (or $\mathrm{Pt}$ )-containing calcium phosphate coatings formed by micro-arc oxidation," Journal of Biomedical Materials Research A, vol. 88, no. 1, pp. 246-254, 2009.

[35] K. Das, S. Bose, A. Bandyopadhyay, B. Karandikar, and B. L. Gibbins, "Surface coatings for improvement of bone cell materials and antimicrobial activities of Ti implants," Journal of Biomedical Materials Research B, vol. 87, no. 2, pp. 455-460, 2008.

[36] X. Bai, K. More, C. M. Rouleau, and A. Rabiei, "Functionally graded hydroxyapatite coatings doped with antibacterial components," Acta Biomaterialia, vol. 6, no. 6, pp. 2264-2273, 2010.

[37] K.-J. Kim, W. S. Sung, B. K. Suh et al., "Antifungal activity and mode of action of silver nano-particles on Candida albicans," BioMetals, vol. 22, no. 2, pp. 235-242, 2009.

[38] P. G. Mendes, M. L. Moreira, S. M. Tebcherani et al., " $\mathrm{SnO}_{2}$ nanocrystals synthesized by microwave-assisted hydrothermal method: towards a relationship between structural and optical properties," Journal of Nanoparticle Research, vol. 14, no. 3, article 750, 2012.

[39] T. Badapanda, S. K. Rout, L. S. Cavalcante et al., "Optical and dielectric relaxor behaviour of $\mathrm{Ba}\left(\mathrm{Zr}_{0.25} \mathrm{Ti}_{0.75}\right) \mathrm{O}_{3}$ ceramic explained by means of distorted clusters," Journal of Physics D, vol. 42, no. 17, Article ID 175414, pp. 1-9, 2009.

[40] T. Bak, J. Nowotny, N. J. Sucher, and E. Wachsman, "Effect of crystal imperfections on reactivity and photoreactivity of $\mathrm{TiO}_{2}$ (Rutile) with oxygen, water, and bacteria," Journal of Physical Chemistry C, vol. 115, no. 32, pp. 15711-15738, 2011.

[41] A. Bielanski and W. C. D. Hare, "Investigation of some antimicrobial procedures on the in vitro development of early murine embryos aimed toward developing methods for the disinfection of mammalian embryos prior to transfer," Journal of In Vitro Fertilization and Embryo Transfer, vol. 8, no. 1, pp. 24-32, 1991.

[42] J. P. Kehrer, "The Haber-Weiss reaction and mechanisms of toxicity," Toxicology, vol. 149, no. 1, pp. 43-50, 2000. 

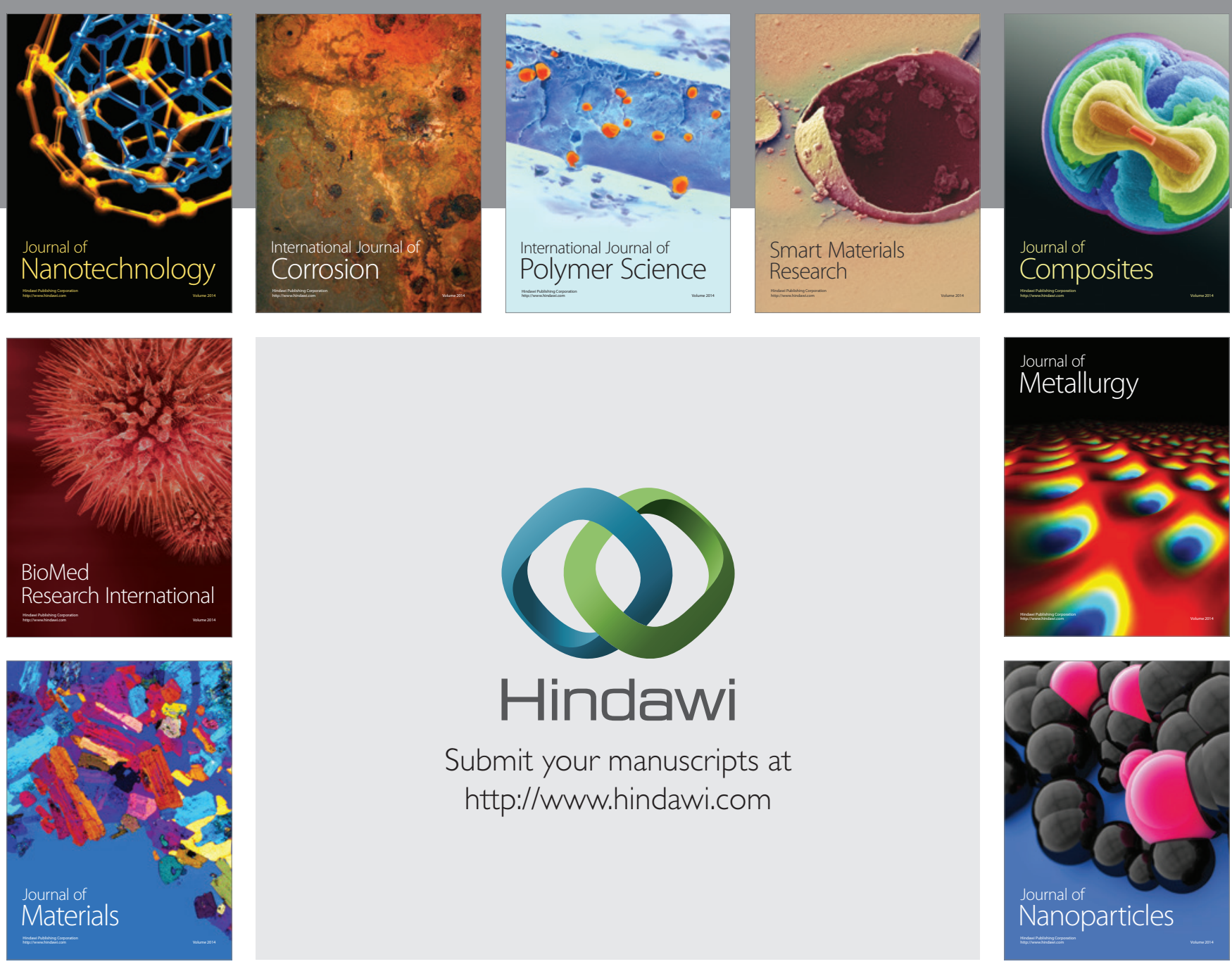

Submit your manuscripts at http://www.hindawi.com
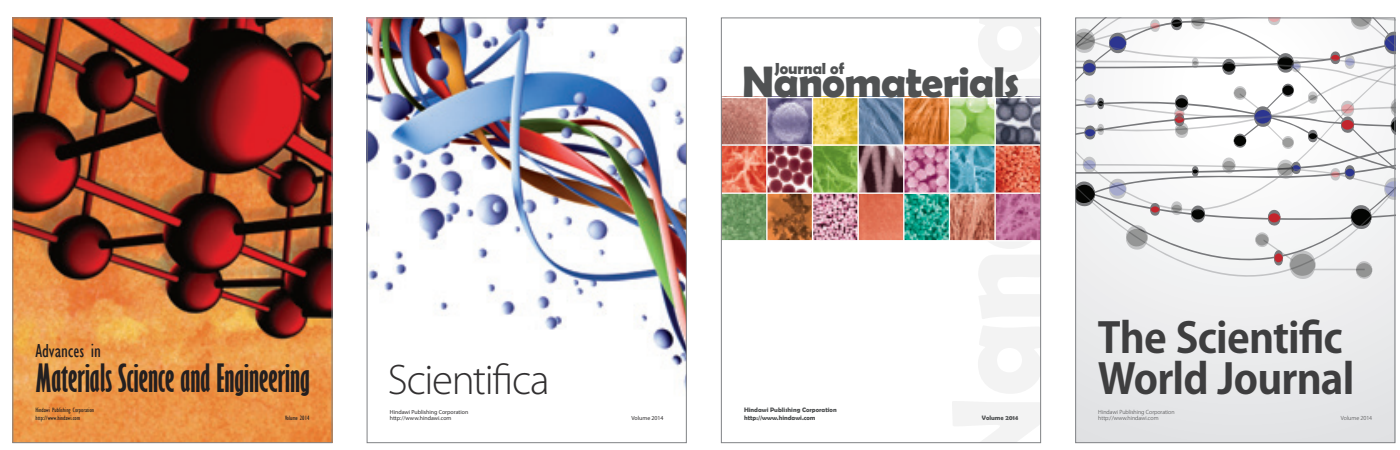

\section{The Scientific World Journal}
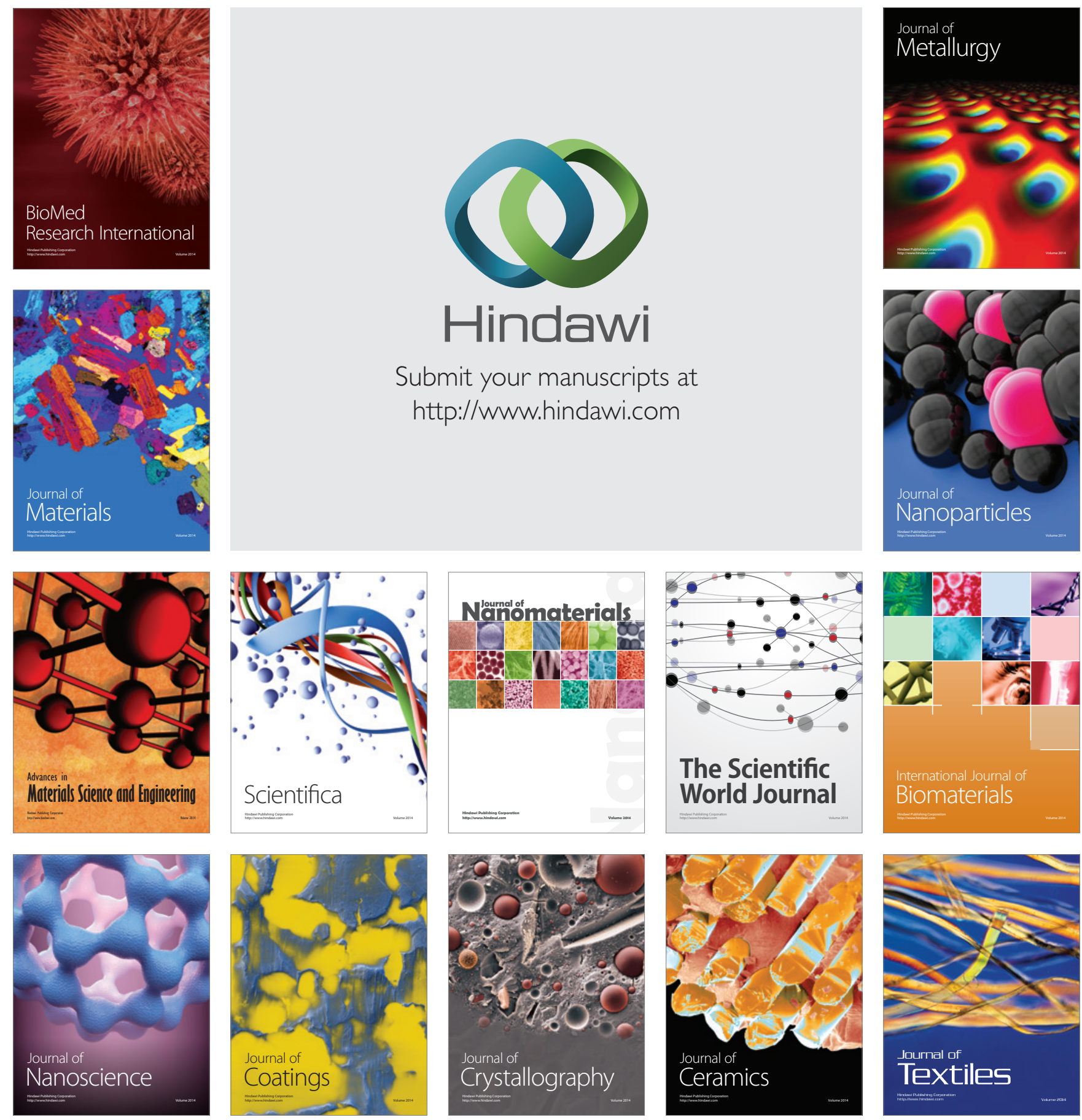